\title{
Giant axonal neuropathy: normal protein composition of neurofilaments
}

\author{
V IONASESCU, ${ }^{*}$ CH SEARBY,${ }^{*}$ P RUBENSTEIN,$\dagger$ A SANDRA, $\ddagger$ P CANCILLA,$\S$ \\ J ROBILLARD*
}

From the Departments of Pediatrics, ${ }^{*}$ Biochemistry, $\dagger$ Anatomy, $\ddagger$ Pathology, $\S$ University of Iowa Hospitals, Iowa City, Iowa, USA

SUMMARY A 14-year-old boy had progressive weakness and ataxia since two years of age with tightly curled hair, facial diplegia, distal weakness and hypaesthesia, cerebellar syndrome and normal intelligence. He also had distal renal tubular acidosis manifested by metabolic acidosis. Sural nerve ultrastructure showed numerous giant axons packed with neurofilaments. The neurofilament major proteins of 68000,160000 and 210000 daltons found in normal sural nerve were also present in the diseased nerve indicating that the protein composition of neurofilaments which accumulates in this disorder has not been appreciably altered. The amount of 68000 dalton neurofilament protein was two times higher in giant axonal neuropathy nerve than in the control nerve. Our results suggest that the neurofibrillary pathology in giant axonal neuropathy is due to a build-up of normal neurofilaments.

Giant axonal neuropathy is a rare autosomal recessive inherited neuropathy of childhood with chronic, slow deterioration. ${ }^{1-6}$ The disease has been also described in dogs. ${ }^{78}$ It has characteristic pathological features with numerous swollen axons distended by an increased number of neurofilaments. The disorder affects also the central nervous system, particularly the brain stem and cerebellum. ${ }^{9-12}$ We report here a biochemical investigation on the neurofilament proteins in the sural nerve of a new case of giant axonal neuropathy.

\section{Case report}

A 14-year-old adopted boy was first seen in January 1973 for evaluation of ataxia and leg weakness. The patient had had curly hair since birth. His developmental milestones were normal for the first two years of life. He then developed slowly progressive weakness of his extremities and ataxia. In addition, he showed failure to thrive and

Address for reprint requests: Dr V Ionasescu, Pediatrics, University of Iowa Hospitals, Iowa City, Iowa 52242, USA.

Received 26 October 1982 and in revised form 25 January 1983. Accepted 7 February 1983 grow and rare episodes of vomiting and obtundation lasting 24-48 hours with spontaneous remission. Physical evaluation revealed height and weight below the third centile and tightly curled hair. Neurological examination showed distal weakness and atrophy of his extremities, areflexia and glove and stocking hypaesthesia. His gait was waddling, unsteady and in a semi-crouched position. He could not walk on his heels or toes. He also showed facial diplegia, cerebellar syndrome, and gaze nystagmus. His intelligence was normal. Other findings included thoracic kyphoscoliosis, pectus carinatus, coxa valga, pes planovalgus, and ichthyosis. His condition has shown slight worsening of weakness and ataxia during the period of 1973-82. The episodes of obtundation and failure to grow were related to distal renal tubular acidosis and subsided after daily bicarbonate treatment.

\section{Methods}

Portions of the biopsied sural nerve were embedded in paraffin and stained with haematoxylin and eosin, luxol fast blue, periodic acid-Schiff with and without diastase digestion and trichrome for light microscopy and in Epox 812 for electron microscopy. Isolation of neurofilamentenriched fractions from fragments of sural nerve belonging to the patient with giant axonal neuropathy and to an age and sex matched control and sodium dodecyl sulphate polyacrylamide gel electrophoresis (SDS-PAGE) of 
neurofilaments followed the procedures described by Julien et al. ${ }^{13}$ Slab gel electrophoresis of purified neurofilaments: neurofilament protein used as a standard for mapping was purified from bovine brain by the method of Chiu et al. ${ }^{14}$ Electrophoresis of the purified neurofilament protein was carried out by the method of Laemmli. ${ }^{15}$ Enzymatic proteolysis of filament proteins using $S$ Aureus $\mathbf{V} 8$ protease was done as described by Chiu et al, ${ }^{14}$ except that the discontinuous buffer system described by Laemmli ${ }^{15}$ was used. The patient's 68000 molecular weight protein bands from the disc gels were also used for peptide mapping in the same manner as the bands from the slab gels. The proteolytic gels were stained according to the silver staining procedure of Merrill et al. ${ }^{16}$

\section{Results}

\section{PATHOLOGY}

The light microscopic sections showed some subperineureal oedema and a loss of large myelinated fibres. These were randomly distributed eosinophilic spheroids representing enlarged axon segments. Cross-sections of the nerve fibres examined by electron microscopy (fig 1) showed striking enlargement of the axon which was filled with closely packed neural filaments. The skeletal muscle was examined with standard histological and histochemical techniques and showed neurogenic atrophy with groups of atrophic fibres and histochemical evidence of reinnervation with fibre type grouping. Skin fibroblast cultures showed normal ultrastructure.

\section{BIOCHEMISTRY}

The neurofilament proteins found in the normal nerve were also present in the diseased nerve (fig 2). The 68000 dalton neurofilament protein was represented by a large peak which was approximately two times higher in giant axonal neuropathy nerve

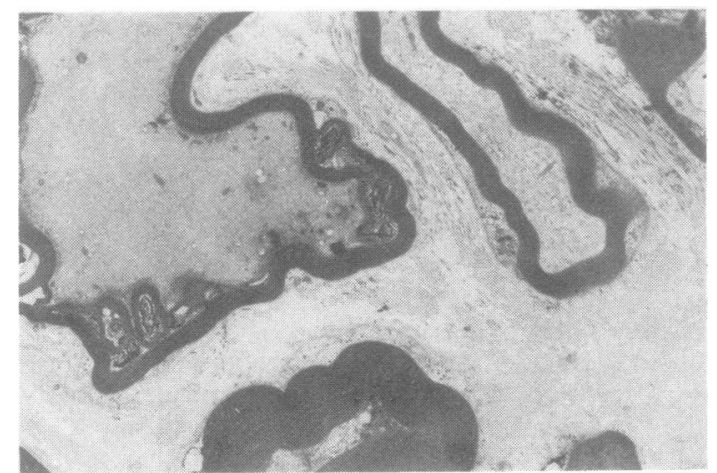

Fig 1 Myelinated fibre in cross-section with giant axonal enlargement due to an increase in neural filaments. $A$ portion of a normal myelinated fibre is present at one side, $\times 7500$.

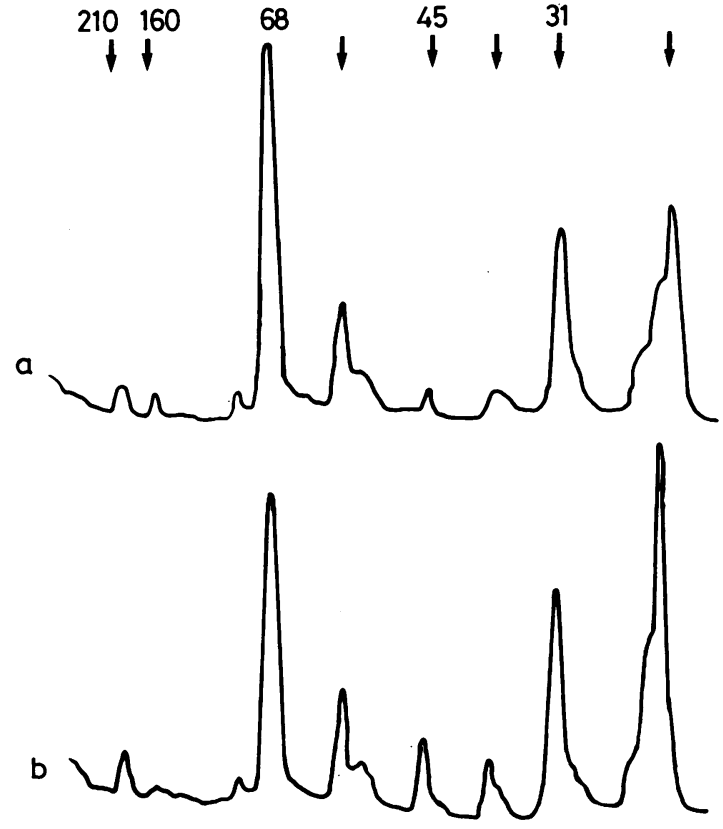

Fig 2 Densitometric scanning of sodium dodecyl sulphate polyacrylamide gel from giant axonal neuropathy and control nerve. The 68000 dalton neurofilament protein is approximately 2 times higher in giant axonal neuropathy nerve (a) than in control nerve (b).

than in the control nerve, based on ratios of the integrated peak areas in the electrophoretogram. The 160000 and 210000 daltons neurofilament proteins were represented by small peaks. Peptide mapping studies showed that the 68000 dalton protein from the giant axonal neuropathy nerve was identical to the 68000 dalton neurofilament protein from normal human nerve. Peptide mapping revealed also that the 68000 dalton protein had a different structure from serum albumin and allowed us to rule out the contamination with the latter protein (data not shown). The 50000 dalton protein isolated by us in addition to neurofilament proteins represented either a glial fibrillary acidic protein or a protein related to Schwann cells.

Renal function tests measured distal nephron $\mathrm{H}^{+}$ secretion by measuring the difference between the $\mathrm{pCO}_{2}$ of alkaline urine and the plasma $\mathrm{pCo}_{2}$. It is assumed that normal subjects will have a difference in the range of $33 \pm 3 \mathrm{~mm} \mathrm{Hg}$ or higher and that patients with distal renal tubular acidosis (RTA) will have values below $10 \mathrm{~mm} \mathrm{Hg} .{ }^{17}$ Our patient had a value of $7 \mathrm{~mm} \mathrm{Hg}$ which was in favour of distal renal tubular acidosis. 


\section{Discussion}

Our case demonstrated the typical signs of giant axonal neuropathy with tightly curled hair and peripheral neuropathy. The biopsy of sural nerve revealed the giant enlarged axons distended by neuropathy neurofilament masses.

There is good clinical and laboratory evidence for central nervous system involvement in the disease in addition to the peripheral manifestations. His findings of head CT scan, EEG, somatosensory and visual evoked potentials, illustrate the spreading of the pathologic process to brain structures, similar to other reports on giant axonal neuropathy.9-12 The episodes of obtundation deserve special attention. A careful laboratory study demonstrated metabolic acidosis which could be related to distal renal tubular acidosis. This is probably a coincidental finding. No previous giant axonal neuropathy cases showed this alteration. However, the possibility of involvement of renal nerves by the same pathologic process as in peripheral nerves cannot be ruled out. DiBona $^{18}$ reviewed the evidence for direct neurogenic control of renal tubular function, specially the sodium reabsorption. The continuous bicarbonate treatment has controlled well the metabolic acidosis in our patient and normalised his growth.

Other atypical symptoms presented by our patient include bilateral vocal cord paralysis due to weakness of laryngeal nerves, skeletal abnormalities (thoracic kyphoscoliosis, pectus carinatus, coxa valga, pes planovalgus) and ichthyosis. The progression of the disease in our case has been extremely slow. During the nine years of follow up we noticed only minimal deterioration, similar to the case reported by Dooley et al. ${ }^{6}$

The concept of giant axonal neuropathy as "generalised disorder of cytoplasmic microfilament formation"19-22 is not supported by the normal ultrastructure of cultured skin fibroblasts in our patient as well as by the fact that actin levels in these cells appeared normal on the basis of gel electrophoretic studies (data not shown). Our results indicate that the neurofibrillary pathology in human giant axonal neuropathy is due to a build up of normal neurofilaments. Similar results were reported in dog giant axonal neuropathy by Julien et al. ${ }^{13}$ This may occur as a result of increased synthesis of neurofilaments or as a consequence of their decreased breakdown. The latter may be related either to a defective protease ${ }^{22}$ or to a defect of a control protein involved in the structural organisation of intermediate filaments as suggested by $\mathrm{Pe}$ na. ${ }^{23}$ Another possible defect in giant axonal neuropathy is metabolic alteration (interruption in the glycolytic pathway?) of slow axonal transport. ${ }^{24}$ This means that neurofilaments synthesis and degradation may be normal but a block of slow transport which carries neurofilaments along axons could explain axonal accumulation in this disease.

\section{References}

' Asbury AK, Gale MK, Cox SC. Giant axonal neuropathy-a unique case with segmental neurofilaments masses. Acta Neuropathol (Berl) 1972;20:237-47.

${ }^{2}$ Carpenter S, Karpati G, Andermann F. Giant axonal neuropathy. A clinically and morphologically distinct neurological disease. Arch Neurol 1974;31:312-6.

${ }^{3}$ Ouvrier RA, Prineas J, Walsh JC. Giant axonal neuropathy - a third case. Proc Aust Assoc Neurol 1974;II:137-44.

${ }^{4}$ Jedrzejowska H, Drac $\mathrm{H}$. Infantile chronic peripheral neuropathy with giant axons. Report of a case. Arch Neuropathol (Berl) 1977;37:213-7.

${ }^{5}$ Takebe T, Koide N, Takahashi G. Giant axonal neuropathy: report of two siblings with endocrinological and histological studies. Neuropediatrics 1981;12:392-404.

${ }^{6}$ Dooley JM, Oshima Y, Becker LE. Clinical progression of giant axonal neuropathy over a twelve year period. Can J Neurol Sci 1981;8:321-3.

${ }^{7}$ Duncan ID, Griffiths IR. Canine giant axonal neuropathy. Vet Rec 1977;101:438-41.

${ }^{8}$ Duncan ID, Griffiths IR. Carmichael S. Inherited canine giant axonal neuropathy. Muscle Nerve 1981;4:223-7.

9 Igisu H, Ohta M, Tabira T. Giant axonal neuropathy. A clinical entity affecting the central as well as the peripheral nervous system. Neurology (Minneap) 1975;25:715-21.

${ }^{10}$ Waters G, Karpati G, Carpenter S. Giant axonal neuropathy (GAN). A disorder of the central and peripheral nervous system: Clinical, neurophysiological and ultrastructural findings in two patients and review of five previous cases. J Neurol Sci 1978;5:340-1.

"Larbrisseau A, Jasmin G, Hausser C. Generalized giant axonal neuropathy. A case with features of FazioLonde disease. Neuro-pädiatrie 1979;10:76-86.

${ }^{12}$ Mizuno Y, Otsuka S, Takano Y. Giant axonal neuropathy. Combined central and peripheral nervous system disease. Arch Neurol 1979;36:107-8.

${ }^{13}$ Julien JP, Mushynski WE, Duncan ID, Griffiths IR. Giant axonal neuropathy: Neurofilaments isolated from diseased dogs have a normal polypeptide composition. Exp Neurol 1981;72:619-27.

${ }^{14}$ Chiu FC, Korey B, Norton WG. Intermediate filaments from bovine, rat and human CNS: Mapping analysis of the major proteins. J Neurochem 1980;34:1149-59.

${ }^{15}$ Laemmli UK. Cleavage of structural proteins during the assembly of the head of bacteriophage $\mathrm{T}_{4}$. Nature . 1970;227:680-5.

${ }^{16}$ Merrill CR, Goldman D, Sedman SA. Ultrasensitive stain for proteins in polyacrylamide gels shows re- 
gional variation in cerebrospinal fluid proteins. Science 1981;11:1437-8.

${ }^{17}$ Halperin ML, Goldstein MB, Haig A. Studies on the pathogenesis of type I (distal) renal tubular acidosis as revealed by the urinary $\mathrm{PCo}_{2}$ tensions. J Clin Invest 1974;53:669-77.

${ }^{18}$ DiBona GF. Neural control of renal tubular sodium reabsorption in a dog. Fed Proc 1978;37:1214-6.

${ }^{19}$ Prineas JW, Ouvrier RA, Wright RG. Giant axonal neuropathy: A generalized disorder of cytoplasmic microfilament formation. J Neuropath Exp Neurol 1976;35:458-70.

${ }^{20}$ Peiffer J, Schlotte W, Bischoff A. Generalized giant axonal neuropathy. A filament forming disease of neuronal, endothelial, glial and Schwann cells in a patient without kinky hair. Acta Neuropathol (Berl) 1977;40:213-8.

${ }^{21}$ Koch T, Schultz P, Willizuns R, Lampert P. Giant axonal neuropathy: a childhood disorder of microfilaments. Ann Neurol 1977;1:438-51.

${ }^{22}$ Pant HC, Gainer H. Properties of a calcium activated protease in squid axoplasm which selectively degrades neurofilament proteins. $J$ Neurobiol 1980;11:1-12.

${ }^{23}$ Pena SDJ. Giant axonal neuropathy: Intermediate filament aggregates in cultured skin fibroblasts. Neurology (Minneap), 1981;31:1470-3.

${ }^{24}$ Spencer PS, Sabri MI, Schaumburg HH. Does a defect of energy metabolism in the nerve fiber underline axonal degeneration in polyneuropathies? Ann Neurol 1979;5:501-7. 